\title{
De la colaboración a la cooperación desde un sentido de corresponsabilidad, las miradas hacia el futuro, uno de los grandes retos de la Gestión Escolar
}

From collaboration to cooperation from a sense of co-responsibility, looks to the future, one of the great challenges of School Management

\author{
Gabriel E. Lara-Abad ${ }^{a}$
}

\begin{abstract}
:
In a classical perspective of school management, the figure of the manager was perceived, for years, as the material author of most of the changes perceived in the center. The classic studies of management place the figure of the manager as a messiah, a subject who possessed, based on experience or innate manner, masterful skills for the exercise of leadership, (understood as a one-dimensional process in this stage of knowledge), the negotiation, the imposition of respect to the norms and rules, as well as the decision making that in their hands were, without a doubt, the suitable ones to solve the internal or external conflicts of the school
\end{abstract}

\section{Keywords:}

Scholl management, director's types, teacher's skills

\section{Resumen:}

En una perspectiva clásica de la gestión escolar, la figura del directivo se percibía, por años, como el autor material de la mayoría de los cambios que se perciben en el centro. Los estudios clásicos de gestión colocan a la figura del directivo como un mesías, un sujeto que posee, a base de experiencia o de manera innata, habilidades magistrales para el ejercicio del liderazgo, (entendido como un proceso unidimensional en este estadio del conocimiento), la negociación, la imposición de respeto a las normas y reglas (que generalmente él designaba), así como la toma de decisiones que en sus manos eran, sin duda, las adecuadas para resolver los conflictos internos o externos de la escuela.

\section{Palabras Clave:}

Gestión Escolar, tipos de directivos, habilidades docentes

\section{Introducción}

En un breve análisis retrospectivo sobre la visión de la gestión escolar en México y sobre estilos de gestión específicamente, no se contaba, hasta hace pocos años, con estudios formales sobre la forma en que se gestó el concepto y cómo se introyectó a lo largo de los años, desde la creación de la SEP hasta nuestros días, que bien pudiera ser objeto de un estudio, pero que para los fines que se siguen en este trabajo sólo es conveniente mencionarlos de manera general.

La Gestión Escolar, cómo término formal, se inserta por vez primera dentro de un documento oficial en este contexto y distintos momentos, surgen iniciativas de diferentes sectores de la educación básica en el país alrededor de la gestión escolar, siendo pioneros los casos del Consejo Nacional Técnico de la Educación (1992-93), Chihuahua (1995), Guanajuato (1995), Coahuila (1995), Estado de México (1996), Baja California (1996), Colima (1996) y Quintana Roo (1996), sumándose en 1997 los Programas Compensatorios para Abatir el Rezago Educativo (conocidos primero como PIARE y luego como PAREIB). 3

En este contexto, el tema de la gestión escolar se ha ido posicionando en el arenga de la política educativa, prueba de ello es que hacia el año 2001, en el Programa Nacional de Educación (2001-2006) y en algunos Programas Estatales (Sonora, Quintana Roo, Baja California, Guanajuato, entre otros) se presentan iniciativas de normatividad, reflexiones, valoraciones, y acciones para mejorar la calidad educativa mediante la transformación de la gestión escolar. 3 
De igual manera, el PNE 2001-2006 expresa una definición de escuela de calidad a la que se aspira (una nueva escuela pública) evidenciando la importancia que se otorga a la organización y funcionamiento del plantel para la mejora de la calidad de los aprendizajes

\section{Hacia una nueva escuela pública}

\section{HACIA UNA NUEVA ESCUELA PÚBLICA}

En primer lugar, la escuela a la que aspiramos habrá de funcionar regularmente. Es decir, cumplirá con el calendario y la Jornada escolar se destinará de manera óptima al aprendizaje. La escuela contará con los servicios y recursos necesarios y suficientes para el desarrollo de las actividades que le son propias. La comunidad escolar tendrá la capacidad de gestión necesaria ante los órganos administrativos correspondientes para asegurar la dotación oportuna, adecuada y suficiente de los materiales, recursos e infraestructura necesarios para su operación regular, y éstos serán aprovechados eficientemente y sin dañar el medio ambiente. Además, constituirá una unidad educativa con metas y propósitos comunes, a los que se habrá llegado por consenso; estilos de trabajo articulados y congruentes, así como propósitos y reglas claras de relación entre los miembros de la comunidad escolar. La comunidad educativa de la nueva escuela pública convivirá democráticamente y sus miembros participarán en la identificación de los retos y en la aplicación de soluciones razonadas, establecidas por consenso, de los problemas que enfrentan.

A partir de la realización de un diagnóstico de las características de los alumnos, la escuela diseñará y pondrá en marcha medidas específicas para remontar las dificultades, atender la diversidad y brindar el apoyo necesario a los alumnos en riesgo de fracaso escolar. De la misma manera, se procurará que en la escuela se definan y cumplan normas de convivencia que permitan y favorezcan el trato digno, la libre expresión, la participación en la toma de decisiones que afectan a todos, la equidad y la justicia en la vida cotidiana escolar. Para lograr esto, es preciso que exista una eficaz colaboración profesional entre los docentes, al igual que entre éstos y el personal directivo y de apoyo (incluyendo la supervisión y los asesores técnico-pedagógicos). El conjunto de los profesores y directivos de la escuela asumirán la responsabilidad por los resultados educativos alcanzados en el transcurso del ciclo escolar y rendirá cuentas a los beneficiarios del servicio (los alumnos y sus padres) por el desempeño de la escuela en su conjunto. El interés y el derecho de los padres y madres a participar en la tarea educativa serán reconocidos y aprovechado por la escuela. Ésta establecerá mecanismos para alentar su participación y canalizar adecuadamente sus esfuerzos, sin que ello signifique que se les delegan las responsabilidades profesionales de la formación de los alumnos. El ejercicio de un liderazgo efectivo por parte del director es esencial para asegurar el cumplimiento de la misión de la escuela.

El director se encargará de promover la colaboración profesional de los profesores; de fomentar la participación, activa y responsable, de los padres y madres de familia; de propiciar el diálogo con la comunidad sobre los propósitos de la educación y sobre las formas de mejorar el funcionamiento de la escuela y los resultados de la educación; de estimular el buen desempeño de los maestros y su interés en que se alcancen las metas que se ha trazado la escuela; de generar un clima escolar que favorezca los aprendizajes al igual que la convivencia armónica, el aprecio por la diversidad y la cultura de la legalidad y la conservación de la calidad del ambiente y los recursos naturales. 11

En la labor de colocar la gestión escolar como medio por el cual se debe coadyuvar a concretar, mantener y elevar la calidad educativa, se han escrito un buen número de trabajos para explicarle, aterrizarla en las realidades específicas de cada centro y elevarla como proceso necesario para el cambio. Sin embargo, poco se ha hablado de la actividad del directivo como agente de cambio, que a partir de su construcción y los procesos psicosociales que le acompañan a lo largo de su vida profesional, sin dejar atrás los modelos formativos que adopta para el ejercicio de sus funciones.

Estas construcciones tienen orígenes diversos y en teorías que explican el surgimiento de actitudes y habilidades que pueden formar una estructura adecuada al perfil que se pretende cubrir.

Se toca inicialmente el tema del proceso de los interaccionismos simbólicos, que sin lugar a dudas han generado un precedente en el modelo de la sociología actual y que con base en la psicología de grupos dan cuenta de la labor de construcción del sujeto.

\section{El interaccionismo simbólico: La vía del cambio entre el ser y el hacer}

El término interaccionismo simbólico fue acuñado en 1937 por Herbert Blumer, quien establece la función básica de esta conceptualización. Si la conducta de las personas se halla vinculada al significado que tengan las cosas, lo que signifiquen las cosas para el sujeto va a depender de su interacción social con otros actores de su entorno y, en definitiva, de los significados aprendidos en su experiencia social interactiva. 2

A través del tiempo, por medio del manejo interno de símbolos, que son aprendidos e introyectado en las estructuras sociales que le empatan con sus pares y la forma de organización de conocimientos aprendidos, el directivo llega a definir conductas y situaciones, 
atribuyéndoles significados precisos y adecuados a cada circunstancia del trabajo que realiza, desde docente hasta la administración escolar. El individuo, por tanto, no es considerado como un mero receptor pasivo de estímulosrespuestas, ni tampoco un procesador mecánico desvinculado de significados colectivos, al contrario, es visto como un constructor activo de significados, organizados éstos de manera dinámica en torno a procesos compartidos de interacción.

El trabajo de George Herbert Mead, en las primeras décadas del siglo XX, supone el comienzo de la orientación teórica del interaccionismo simbólico, término que él no acuñó, aunque es considerado su padre intelectual. En síntesis, el pensamiento de Mead afirma que la persona emerge de la interacción social a través, fundamentalmente, del lenguaje y en la forma de interacción simbólica. Mead (1934-1993) explica detalladamente el desarrollo del sí mismo y recalcó que la autoestima y la noción de uno mismo se originan, se mantienen y se modifican a través de la interacción social. 9

Para Mead, la interacción social está se regula a través de símbolos con significado preciso; para el directivo en construcción los símbolos presentes en la interacción que se le apercibe a lo largo de su formación le permiten recibir información sobre sí mismo a partir de los otros y, lo que es más importante, anticiparse al cómo reaccionarán los demás ante su conducta, todo ello mediante un proceso de comprensión de los roles sociales, las normas sociales sobre cómo debería comportarse en el desempeño de su puesto, permiten predecir con éxito de qué manera se van comportar, además de favorecer en uno mismo la adquisición de los roles. En efecto, el aprendizaje de la conducta apropiada a cada rol supone una interiorización de la sociedad dentro del individuo. 9 Éste puede, entonces, desplazarse fuera de sí mismo y evaluar sus características y su conducta. Por ejemplo, en el la entrevista citada anteriormente la maestra directora era buena/mala de acuerdo a la percepción simbólica de los sujetos que lo acompañaban en su labor en la escuela.

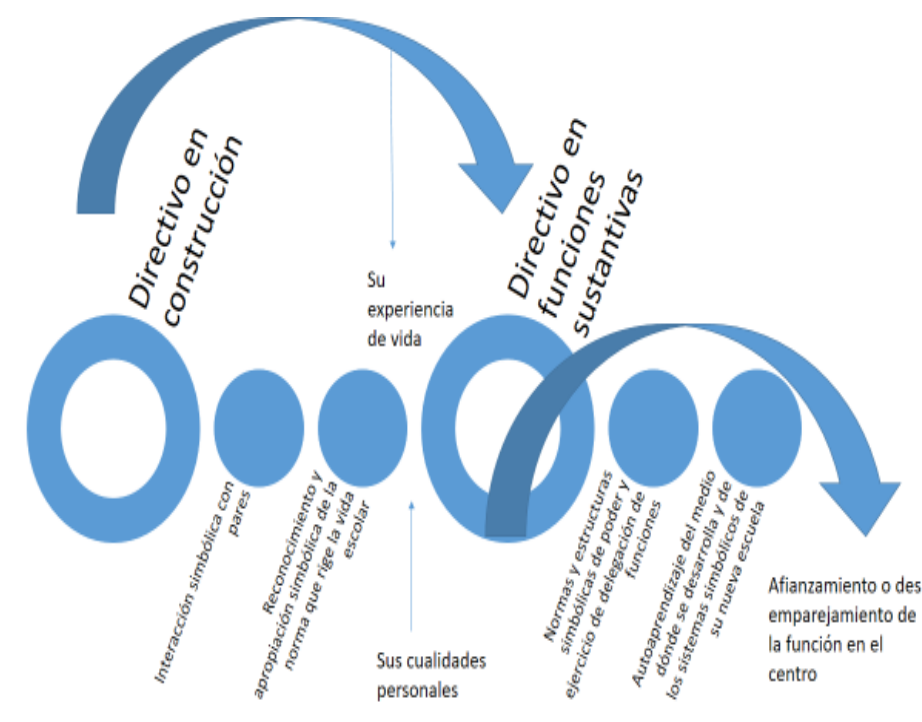

Fig. 1

Cuando un docente se ve como prospecto a un puesto directivo

En este caso, como se ejemplifica en la figura 1, el directivo en construcción introyectó de manera sustantiva elementos del medio social y simbólico de las relaciones con los pares y las normas, su tránsito, con base a la forma estructurada del interaccionismo simbólico, transcurre en un devenir enfocado en la apropiación y adecuación de elementos internos y externos que se combinan y construyen a partir de sus experiencias de vida y sus cualidades personales de las que se hablará más tarde, como los estilos de liderazgo.

Al aprobar el examen de promoción, obtener el nombramiento y ya en funciones, normas y estructuras simbólicas de poder y el ejercicio de delegación de funciones a partir de lo que los lineamientos y su experiencia le indican, pueden interactuar con el nuevo modelo social (escuela asignada). Así, se puede observar que un directivo, analizando su historia, su personalidad y sus interacciones, puede constituirse como un elemento de gran valor para el centro en el que ejerza sus funciones, ya que toma elementos constructivos existentes en el nuevo espacio en el que se integra, así como los procesos sociales que se llevan a cabo en la interacción de la dinámica escolar (Capítulo anterior de la tesis).

Con base en el sistema teórico del interaccionismo simbólico se observan en la obra de Mead, que el todo social precede a la mente individual lógica $y$ temporalmente, el individuo consciente y pensante es lógicamente imposible sin un grupo social que le precede. El grupo social es anterior, y es él el que da lugar al desarrollo de estados mentales auto consciente.

Mead explica en su teoría que el acto debe verse como la unidad básica de sus postulados, no es en sí un hecho emergente, sino la base de toda emergencia. En otras palabras, el acto es la base de donde salen a la luz todos 
los aspectos del análisis de lo simbólico. En su análisis del acto se acerca al enfoque del conductista y se centra en el estímulo y la respuesta, creía que el estímulo no provocaba una respuesta automática en el ser humano. Identificó cuatro fases fundamentales e interrelacionadas del acto; las cuatro representan un sistema.

La primera fase es la del impulso, que entraña un estímulo sensorial inmediato y la reacción del actor al estímulo, la necesidad de hacer algo como respuesta. En el caso de la figura directiva, ante una amenaza o una agresión que puede ser percibida como un estímulo aversivo y con el bagaje de experiencias previas, que pudiera poner en riesgo su autoridad frente a un miembro de la comunidad, reaccionará, de acuerdo al nivel de intensidad de este estímulo. Theodore Fechtner establece este fenómeno correlacionando variables físicas con variables psicológicas:

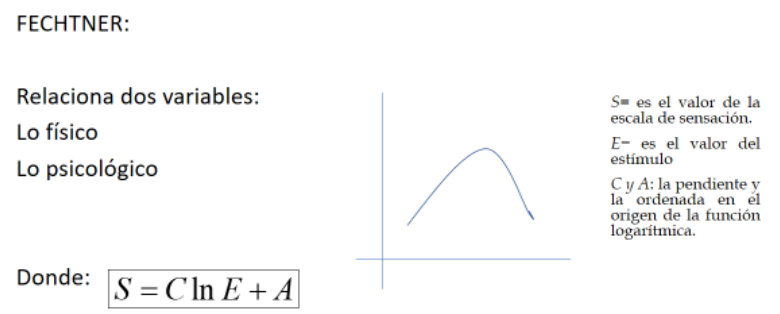

En esta línea, Fechtner establece que la relación con la forma entre la percepción del sujeto con relación al objeto actitudinal que se le presenta, de tal manera que el Valor de la escala de sensación (S) es igual al movimiento de la función con relación al estímulo.

En este primer momento, el impulso se analiza desde la perspectiva conductual, sin embargo en la segunda fase de este proceso, el acto, que se entiende como la percepción, en la que el directivo busca y reacciona a un estímulo relacionado con el impulso.

La percepción implica tanto los estímulos entrantes como las imágenes mentales que se generan ante los estímulos y percepciones mentales que se gestan en el directivo. En tal caso el directivo no responde simple e inmediatamente a los estímulos externos, como pudiera pensarse, sino que más bien considera y sopesan la respuesta a través de imágenes mentales que en el momento de estar expuestos ante un estímulo se presentan ante ellos.

Cabe mencionar que el directivo no está expuesto sólo a la estimulación externa; también selecciona activamente las características de un estímulo y elige entre un abanico de respuestas, según sea el caso. Es decir, un estímulo puede tener varias dimensiones, y el directivo es capaz de elegir entre ellas. Además, por lo general, se topa con muchos estímulos, y tiene la capacidad de elegir unos y descartar otros.
La tercera es la fase de la manipulación. Una vez que se ha manifestado el impulso y el objeto ha sido percibido, el siguiente paso es la manipulación del objeto o, en términos más generales, la acción que el directivo emprende con respecto a lo que tiene. Además de sus ventajas mentales, el directivo tiene otra ventaja sobre sus compañeros con relación a su actividades y a su ejercicio de toma de decisiones. 2

La última fase, la consumación del acto que, en términos más generales, equivale a emprender la acción que satisface el impulso original. En este caso y con base a las teorizaciones anteriores, se liga esta etapa con la Tarea, que ya está en condiciones de cumplirse a partir de los elementos organizados en las funciones del director frente al grupo. 9

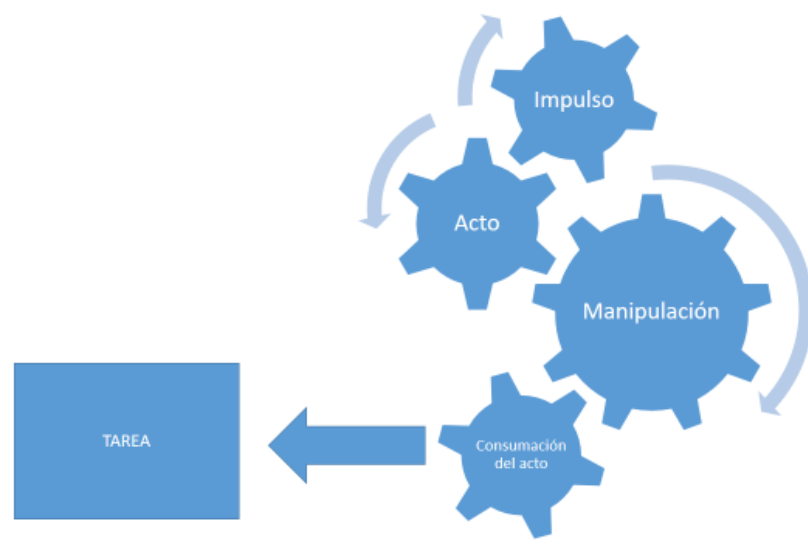

Figura 3

Proceso del modelo de Mede en la construcción de respuestas ante la tarea por parte del directivo

\section{El trabajo simbólico y su interacción con la tarea}

Hablar del símbolo en el proceso de construcción del directivo, precede en parte de la formación de organizaciones actitudinales, experiencias y aprendizajes formales dictados por la norma, es decir, coexisten en el directivo conductas, experiencias sociales $y$ comportamentales, demandas de la norma actual.

Un símbolo significante se define entonces como un acto introyectado que se reproduce en el directivo, y que sólo los seres humanos son capaces de realizar. Los gestos por ejemplo (agrado, desagrado, aprobación, desaprobación, sorpresa o duda) que presenta ante determinados estímulos se convierten en símbolos significantes ( 2 ) cuando surgen de un directivo y que constituyen el mismo tipo de respuesta, no necesariamente identificada con los pares en los que provocará reacciones diversas. Los gestos físicos pueden ser símbolos significantes. Así, son las verbalizaciones o evocaciones y las entonaciones que emite van entonces a convertirse en símbolos significantes, si bien no todas se convierten en ellos. 2 En palabras de Mede, El conjunto 
de gestos vocales que tiene mayor probabilidad de convertirse en símbolos significantes es el lenguaje: «un símbolo que responde a un significado en la experiencia del primer individuo y que también evoca ese significado en el segundo individuo. Cuando el gesto llega a esta situación, se ha convertido en lo que llamamos «lenguaje». 9

\section{La colaboración y la cooperación desde un sentido de corresponsabilidad}

Explicado entonces el proceso de la formación del ente directivo a partir de elementos conductuales, subjetivos y simbólicos que interactúan con el encargo, toca entonces hablar sobre la tarea y en específico, en las funciones que tiene en los procesos de colaboración y cooperación dentro de la escuela. Si bien el directivo se conforma a partir de un cúmulo de elementos intra e inter subjetivos, los elementos propios de su función se congregan en el ejercicio de lo que en otro capítulo se ha hablado, la relación entre pares en un grupo.

Una de las más complejas, por no decir difíciles, tareas que tiene un directivo frente a la tarea es la de promover en su grupo de trabajo los elementos activos de los cambios que provienen de las políticas educativas y que se correlacionan con las actividades cotidianas de su entorno. El directivo es el responsable de comunicar las reformas, cambios y nuevas estructuras de organización del trabajo; debe incentivar a los docentes a participar, trabajar y organizar las tareas que demanda la escuela, considerando la cultura en la que se desenvuelve (signos y símbolos) e impulsar la profesionalización de los docentes para que se apropien de los conocimientos y las herramientas que requieren, así como promover la colaboración en torno a los objetivos educativos que dicta la política educativa en turno, así como buscar los recursos para la escuela a partir de la gestión de elementos normativos y sociales, así se prepara el camino para generar el cambio escolar y con ello mejorar la calidad educativa .10

La función del directivo inserto en el paradigma de los sistemas de colaboración es la de acercar a los miembros del grupo de trabajo, sin importar su afinidad, área de profesionalización, tiempo de servicio, entro muchas otras características de los sujetos de un grupo

Tal cual lo refiere Antúnez la función directiva es compleja porque su acción se origina en las demandas de los distintos componentes de la escuela como institución: de los objetivos, de los recursos humanos, materiales y financieros; de la organización; de la tecnología o modos en que opera; de la cultura escolar (valores, creencias, significados compartidos por los miembros de la institución) y del entorno donde se ubica la escuela . 1 En respuesta a las demandas de la sociedad actual, como ha sucedido en cada época en la que se han establecido acciones para generar un cambio paradigmático en nuestras sociedades, surgen las nociones de participación y colaboración educativa .5 como una herramienta actual que, con base en las exigencias de una sociedad inmersa en la información y la comunicación, se debe trabajar hombro con hombro entre los miembros del colectivo escolar para llegar a comprender, atacar y organizar las acciones encaminadas en la mejora. Atrás queda entonces la idea o acción del directivo acapararte, líder solitario y a veces autocrático que desde el panóptico de su oficina, controlaba la vida educativa del centro.

En el año 2010, la OCDE en "Mejorar las escuelas: Estrategias para la acción en México" marca en su recomendación 11:

Crear liderazgo instrucciones y capacidad docente dentro de las escuelas y grupos de escuelas, promover que las escuelas trabajen juntas en asociaciones o grupos Las escuelas mexicanas trabajan generalmente como unidades independientes y por lo tanto, muchas tienen capacidades limitadas para tener acceso a esquemas de desarrollo profesional de alta calidad basados en las necesidades de la escuela, entre otras tareas de gestión. Las escuelas en donde existen buenas prácticas y de alta calidad deben compartirlas con las escuelas que tienen una capacidad limitada para su propia mejora.

Se ganaría mucho si las escuelas lograran trabajar en conjunto con otras escuelas de manera que pudieran reunir las experiencias de sus docentes, ATP y directores. Algunos ejemplos incluyen: identificar un docente líder en cada área del conocimiento "central" dentro del grupo de escuelas y permitirles un cierto tiempo para trabajar con docentes en otras escuelas; ofrecer formación colectiva local para docentes; compartir planeación y evaluación con el objetivo de mejorar la enseñanza; o agrupar escuelas en asociaciones oficiales, con un director ejecutivo para dirigir cada grupo y responsabilizarse de la rendición de cuentas para la mejora de su desempeño. Es necesario crear nuevas formas de colaboración entre las escuelas. Estas opciones podrían ser: redes 0 federaciones de escuelas, $u$ otras colaboraciones de "escuela-a-escuela", pero también incluiría que algunas escuelas operaran como centros especiales de desarrollo docente, formación y consulta. El establecimiento de un programa nacional de liderazgo podría contribuir a regular la oferta de los cursos para líderes y supervisores escolares. Este programa puede ser gestionado por un grupo de trabajo en cooperación con universidades, la Universidad Pedagógica Nacional y sus unidades estatales, y algunas Normales, para evitar la creación de nuevas estructuras. 7

Se ve entonces inscrito en este proceso que la revisión de la literatura y la organización planteada desde las instituciones internacionales que rigen la vida educativa de las naciones miembros de esta organización, ahora 
bien, como se ha explicado previamente la visión de la construcción del directivo se conjuga con esta forma de percibir la colaboración no como una exigencia sino como un estilo de liderazgo y de acompañamiento en el que la responsabilidad de llevar a bien los mandatos y el encargo a través de la tarea, se conjuguen en un trabajo colaborativo que engarza con las exigencias del medio.

En cuanto a la colaboración, diversos autores nos proporcionan distintas visiones del concepto; hace una distinción entre "colaboración burocrática", entendida ésta como aquella que se mantiene por obligado cumplimiento, y "colaboración espontánea", en la que los miembros que la establecen lo hacen de forma voluntaria por tener intereses comunes. 8 Por su parte la colaboración como un proceso de "transformación social" cuando implica el trabajo conjunto. De este modo, se convierte en uno de los principios más importantes por los que deben regirse las organizaciones educativas. 6 Colaborar o participar significa algo más que intervenir de manera eventual. Es necesario que cuando se establezca, ésta sea voluntaria y requiera una responsabilidad compartida, al poder intercambiar experiencias e incluso herramientas para emprender proyectos en los que se compartan las mismas metas, además de incidir en cambios dirigidos a la mejora.

\section{Conclusiones Visión a Futuro}

Analizado lo anterior y con base al cúmulo de experiencias y saberes que se han congregado en este ensayo, así como las demandas que se tienen desde 1990, 2000 y las visiones de la educación por parte de la UNESCO, la OCDE, la misma SEP y sobre todo, con las modificaciones que la vida actual de las escuelas demanda de los directivos, se dibuja desde hace pocos años y en prospección al futuro, elementos interdisciplinarios para la formación del directivo. En un esfuerzo sin precedente, la Escuela Normal Superior de México, a través de sus licenciaturas y el área de posgrado, así como los colegios de gestión que han ido adecuándose a las exigencias de las leyes y cambios paradigmáticos de las estructuras normativas y sociales, perciben la necesidad de cubrir y cumplir con elementos formativos y aportando al estado del arte del a gestión escolar, nuevas estrategias y organización de saberes que comparten en la vida práctica de las escuelas secundarias. Mirando hacia el futuro, pensando en las metas propuestas para el 2030, la gestión escolar se ve como un ente transdisciplinar y actualizado que ostenta el trabajo de pares que desde distintas ópticas coadyuvan en la mejora de la formación y la adecuación de nuevos saberes y estrategias para el trabajo de la relación con la realidad de cada escuela. Se compromete y se constituye en un marco de legalidad que exige mejoras en la forma en la que la intervención activa de saberes forma e integran nuevos contextos teóricos y prácticos en pro de la escuela. 4

\section{Referencias}

[1] Antúnez, S. (1993). Claves para la Organización de Centros Escolares. ICE-Horsori.

[2] Blumer, H. (2002). Symbolic interaction. Man and society Prince Hall.

[3] Espinosa, R. O. (2012). La gestión escolar en México. Algunos aprendizajes. México DF. Obtenido de http://www.setse.org.mx/ReformaEducativa/recursos_evaluacion/curso _evinterna/materiales/anexos/Bloque\%201/BONILLA_O_GESTION_ ESCOLAR.pdf

[4] García, M. A. (2011). La Función Directiva en Secundarias Públicas Matices de una tarea compleja. México: Instituto Nacional de Evaluación Educativa.

[5] Gutiérrez, Á. M. (2013). Colaboración educativa en la sociedad del conocimiento (Vol. 5). Seville: Revista de innovación educativa.

[6] Katz, S. \&. (s.f.). Learning about networked learning communities. (Vol. 21). chol Effectiveness and School Improvement.

[7] OCDE. (2010). ESTRATEGIAS PARA LA ACCIÓN EN MÉXICO. Mex: OCDE.

[8] Pérez, A. (2002). La cultura escolar en la sociedad neoliberal. Morata.

[9] Ponts, J. (2010). LA APORTACIÓN A LA PSICOLOGÍA SOCIAL DEL INTERACCIONISMO SIMBÓLICO: UNA REVISIÓN HISTÓRICA (Vol. 9). Edupshyke, España.

[10] RUIZ, A. I. (2008). LA PARTICIPACIÓN Y ESTILOS DE GESTIÓN ESCOLAR DE DIRECTORES DE SECUNDARIA (Vol. 13). (R. M. 113, Ed.) México, México: RMIE.

[11] SEP. (2001). Plan Nacional de Educacion 2001-2006. México DF: Diario Oficial de la Federación. 